\title{
Seasonal variation and characteristics of atmospheric particles in Busan, a harbor city in South Korea
}

\author{
SEON-EUN LEE ${ }^{1}$ AND GEUN-HA PARK ${ }^{1}$
}

${ }^{1}$ Korea Institute of Ocean Scicence and Technology, Busan, Repulic of Korea, 49111, selee@kiost.ac.kr, gpark@kiost.ac.kr

East Asia region has increasingly influenced by the emission of air pollutants for more than a few decades arising from rapid industrialization and heavy population in many cities or countries. Busan, one of the metropolitan areas in South Korea, is characterized by its eastern and southern coasts and mid- to large-size trading ports allowing dozens of vessels to arrive, anchor, or depart per day emitting exhaust fumes.

To examine an impact of these anthropogenic emission on coastal marine environment, we have sampled airborne particles throughout a year from March 2019 to February 2020 employing a high-volume air sampler at a site $\left(35.07^{\circ} \mathrm{N}\right.$, $129.08^{\circ} \mathrm{E}$ ) adjacent both to ports and coasts and analyzed concentrations of inorganic soluble ions and nitrate isotopes in the samples.

During this period, monthly mean concentrations of total suspended particles (TSP), PM10, and PM2.5 were normally higher in colder and drier seasons than warmer and wetter seasons like in other neighboring areas. Similar seasonality was shown in monthly concentrations of nitrate and ammonia in TSP as well, while those of chloride and non-sea-salt sulfate (nss-sulfate) were not, with an exception only for chloride temporarily a bit higher in September and October.

Remarkably in summer, three- or four-day-mean concentrations of nss-sulfate occasionally jumped when the winds mainly blew from the southwest. This is likely due to particles that traveled northeastward through the local anchoring points on the sea located south of the sampling site, possibly carrying lots of sulfur emitted from vessels. Higher concentrations of sulfur dioxide gas were also measured at a near observatory located $1.67 \mathrm{~km}$ (a mile) south of our site during the same period. 